\title{
Subjetividade feminista em devir: a individualidade humana de Emma Goldman entre a filosofia e o teatro
}

\author{
Larissa Guedes Tokunaga ${ }^{1}$
}

\begin{abstract}
Resumo: $\mathrm{O}$ feminismo antipredicativo de Emma Goldman incita ao cotejo de seu prisma anarquista com o de uma filosofia de ontologia radical, uma transversalidade que resgata a matriz do ideário anarquista, a saber: o indivíduo. A partir do presente artigo, pretende-se realizar um diálogo entre o conceito de "individualidade humana" propugnado por Goldman e os ideários de Max Stirner e Henrik Ibsen, leituras de cabeceira da autora. A filosofia stirneriana, ao rechaçar as mediações externas, contribuiria para a valorização do "eu" enquanto bastião da revolta contra as instituições hegemônicas, ao passo que o teatro social moderno ibseniano estimularia a anarquista a entrever na arte um instrumento de consciência voltada à autonomia da mulher, a qual passaria a questionar sua objetificação e a se autogovernar enquanto ser humano. O devir, que imprimiria a marca de incongruência em relação a quaisquer modelos programáticos de insurgência, se consubstanciaria em um feminismo antipredicativo crivado pela filosofia e teatro dessubjetivadores/subjetivadores.
\end{abstract}

Palavras-chave: Anarquismo - Feminismo - Subjetividade - Filosofia - Teatro

\section{Feminist subjectivity in becoming: Emma Goldman's human individuality between philosophy and theater}

\begin{abstract}
Emma Goldman's antipredicative feminism incites to connect her anarchist prism with a philosophy of radical ontology, a transversality that recovers a matrix of anarchist ideas: the individual. This article intends to carry out a dialogue between the concept of "human individuality" proposed by Goldman and the ideas of Max Stirner and Henrik Ibsen, the author's bedside readings. An agitating philosophy, to combat external mediations, contribute to the valorization of "individual" against hegemonic institutions, while the modern Ibensian social theater of entertainment urges entry into art an awareness instrument, which would question objectification and self-government as a human being. The device, which prints a mark of incongruity in relation to the programmatic models of insurgency, embodies an antipredicative feminism created by desubjectivating / subjectifying philosophy and theater.
\end{abstract}

Keywords: Anarchism - Feminism - Subjectivity - Philosophy - Theater

\footnotetext{
${ }^{1}$ Mestra em Humanidades, Direitos e Outras Legitimidades pelo Diversitas/USP, Doutoranda pelo mesmo programa e instituição, mediadora do grupo de estudos sobre Anarquismos, Feminismos e Masculinidades pelo Centro de Cultura Social (CCS) e pesquisadora associada ao grupo de estudos do Núcleo de Estudos e Pesquisas sobre Anarquismo e Cultura Libertária (NEPAN - UERJ). Email: lariguetokunaga@gmail.com.

O presente trabalho foi realizado com apoio da Coordenação de Aperfeiçoamento de Pessoal de Nível Superior - Brasil (CAPES) - Código de Financiamento 001
} 


\section{Introdução: por uma individualidade humana}

Compreender o feminismo sem adjetivos de Emma Goldman equivale a perscrutar suas concepções sobre a relação indivíduo/sociedade. Ao enunciar a "individualidade humana" como uma espécie de pedra angular do anarquismo, a militante vai na contracorrente dos binarismos e dicotomias hegemonicamente propalados: feminino/masculino, esfera privada/esfera pública, arte/militância. Situando as individualidades singulares como subjetividades dotadas, todas elas, de um potencial libertário, Goldman subverte as lutas feministas pautadas pelas reivindicações de direitos historicamente estabelecidos por homens e para homens.

O conceito supracitado foi empregado por Emma Goldman no desenvolvimento do artigo The Individual, society and State (1940), originalmente escrito em inglês como man's individuality $^{2}$. No referido ensaio, a autora menciona o anarquista clássico Piotr Kropotkin (1842-1921) em alusão ao mutualismo por ele defendido. O liame que tornaria os sujeitos uma "humanidade", na visão goldmaniana, seria o apreço pela liberdade, a expressão irrevogável da personalidade. Somente a partir da expressão irrestrita da singularidade é que o sujeito poderia se associar voluntariamente a outros. Sendo assim, a possível autonomia da mulher não se localizaria nem em um âmbito isoladamente individual (ao molde do individualista liberal) ou compulsoriamente social (como em um coletivismo socialista), mas em uma espécie de fita de möebius que, inextricavelmente, uniria indivíduo e sociedade em uma continuidade quase orgânica.

Com efeito, Emma Goldman chegaria a rechaçar o que ela designaria como "dualidade dos sexos", criticando a iniquidade patriarcal por meio do apontamento da subsunção da personalidade da mulher à instituição do matrimônio ou ao sufrágio universal como possível alcance da igualdade. Conforme aponta, "a paz ou a harmonia entre os sexos e os indivíduos não depende necessariamente de uma superficial igualação entre os seres humanos, nem tampouco supõe a eliminação dos traços e peculiaridades individuais"4.

Ao defender que a "verdadeira emancipação começa na alma da mulher" ${ }^{5}$, Emma Goldman não propõe uma evasão individualista, mas um "cuidado de si" - como sugeriria Michel Foucault ${ }^{6}$-, que proporcionaria autonomia individual e social concomitantemente. A partir do momento em que os papéis de mãe, esposa, trabalhadora não fossem introjetados como obrigatoriedade moral, a mulher poderia ver a si mesma como liberta enquanto individualidade cujo potencial humano é o de aspirar à expressão sem mediações. Dessacralizar conceitos tidos como abstrações transcendentes está no fulcro da perspectiva goldmaniana de resistência. Não por acaso, seu posicionamento antipatriarcal seria revestido

\footnotetext{
2 Os conceitos e excertos são de livre tradução da autora do artigo. GOLDMAN, The Individual, Society and the State, p. 9.

${ }^{3}$ GOLDMAN, The Tragedy of Woman's Emancipation, p.94.

${ }^{4}$ GOLDMAN, The Tragedy of Woman's Emancipation, p. 91.

${ }^{5}$ GOLDMAN, The Tragedy of Woman's Emancipation, p. 95.

${ }^{6}$ Conceito cunhado pelo filósofo. Não há como elidir o cotejo da obra de Emma Goldman com o aporte teórico-filosófico de Michel Foucault, haja vista que a anarquista citada antecipa grande parte dos conceitos filosóficos por ele elaborados. Autoras especialistas em obras de anarcofeministas, tais como Margareth Rago, já apontaram para a relevância de estabelecer tal diálogo.
} 
por um niilismo ativo: a equidade de direitos não representaria a autonomia, sendo vista como um placebo que apenas mascararia a dominação estrutural do Estado.

Antes mesmo de se atrelar a uma identidade feminista, Emma Goldman postulava a necessidade de se descolar dos modelos previamente programados pelas instituições sociais, tais como a do matrimônio. Ou seja, o desafio de lutar contra os "tiranos internos" do próprio eu está no escopo da autora, o que revela um prisma de autonomia que não depende de chancelas externas. No bojo do ensaio Matrimônio e amor (1911), ela argumentaria:

É essa servil aquiescência à superioridade do homem que manteve a instituição do casamento aparentemente intacta por um tempo tão longo. Mas agora que a mulher está vindo a si, agora que ela está crescentemente consciente de si como um ser exterior à graça do mestre, a sagrada instituição do casamento está gradualmente sendo minada, e nenhum tipo de lamentação sentimental poderá evitar isso. ${ }^{8}$

A consciência de si enquanto indivíduo descolado dos modelos de individualismo, cidadão, homem/mulher é alçada por Goldman a um patamar de insurgência, elegendo-se, pois, os óbices à autonomia feminina: a instituição do matrimônio, o puritanismo e a moral cristã. Esta última, que seria o sustentáculo dos outros entraves sociais, seria entrevista pela anarquista como o cerne da abnegação de si. A renúncia aos desejos subjetivos e ao devir, o qual abre margem a essa expressão irrefreável das singularidades pessoais, seria sublinhada em toda a extensão da obra de Emma Goldman. E é nesse sentido, pois, que a radicalidade de Max Stirner teria uma incursão importante na linha de pensamento goldmaniana.

\section{Filosofia stirneriana e assunção do "eu" como gesto de revolta}

Um dos pontos nodais que conjugam os pensamentos de Max Stirner (1806-1856) filósofo do XIX e leitura de cabeceira da autora - e Emma Goldman é justamente o ceticismo em relação a qualquer espécie de liderança, programa etapista, dogmático, intervenção dirigista que se alçasse como porta-voz dos indivíduos que compõem a sociedade. Conhecido pela publicação da obra $O$ Eu único e sua propriedade (1844), o referido autor, que viveu no apogeu do hegelianismo, se dedica a demolir todos os pilares sobre os quais o homem moderno edificou a racionalidade social: Deus, Estado, Igreja, moral, liberdade, humanidade, matrimônio. De matriz negativa, seu manifesto propõe reconectar o indivíduo à natureza do nada, à materialidade da existência imanente que repele os vernizes sociais artificiais.

Emma Goldman faria menção ao pensamento stirneriano a partir da ênfase ao impulso da revolta individual:

A superstição política ainda influi sobre os corações e mentes das massas ainda que os verdadeiros amantes da liberdade não tenham nada a ver com

\footnotetext{
${ }^{7}$ GOLDMAN, The Tragedy of Woman's Emancipation, p.94.

${ }^{8}$ GOLDMAN, Matrimonio y Amor, p. 95.
} 
isso. Ao contrário, estes últimos acreditarão, com Stimer, que o homem terá tanta liberdade quanto ele quiser tomar. ${ }^{9}$

A premissa de que a consciência individual seria o fator embrionário da mudança social impulsionou Emma Goldman a buscar na subjetividade a medida de um feminismo antipredicativo. O "egoísmo" propugnado por Stirner, ao demolir as mediações socialmente convencionadas e internalizadas pelo próprio sujeito, inspira a militante. A obra de Max Stirner, O Eu Único e sua Propriedade (1844), é formulada como ontologia radical em prol da ruptura com as estruturas sociais da modernidade. Ao enveredar por um esboroamento dos conceitos que se absolutizaram, o autor dirige seu alvo aos ideais e à pretensa realidade moderna que incorporou os espectros religiosos no modelo de humanidade pretensamente racional.

Tal empreitada filosófica - expressamente individualista - pavimentaria caminhos que incitariam Goldman a repensar as formas de resistência anarquistas. No âmago do sujeito estaria depositada a contrahegemonia, de modo que ser livre não significaria lutar por uma liberdade vindoura, mas romper com a anuência individual a conceitos hipostasiados que subscrevem a servidão. Sendo assim, a ênfase que a autora confere à perniciosidade das "superstições" fomentadas e essencializadas pelo Estado, Igreja e moral se coaduna de forma estreita com um movimento no sentido de dessacralizar as instituições modernas e algumas categorias universais a elas atreladas.

Entender o que a autora expõe como a condenação das mulheres à abdicação de suas próprias vidas implica em um paralelo esclarecedor com a ideia de autorreferencialidade defendida por Max Stirner. Ao recusar tudo aquilo que não lhe é próprio, isto é, que cabe apenas à alçada do indivíduo, o autor diagnosticaria que "perante o sagrado perdemos toda a sensação de poder e toda a coragem: comportamo-nos de forma impotente e humilde" ${ }^{10}$. Ou seja, o cerne da submissão estaria em projetar sua existência em um "outro", ponto que Goldman também faria questão de sustentar em relação ao direito sufragista, visto como instância que nem aos próprios homens conferiria autonomia.

A inspiração da obra de Max Stirner para a compreensão de Emma Goldman reside na afirmação da transitoriedade do sujeito, que escaparia a definições. Sua premissa negadora de abstrações faculta a desnaturalização de alguns modelos eleitos como essências biológicas, sobretudo as emergentes em meados do século XIX ${ }^{11}$. Para o filósofo, não há por que se fiar em modelos de um verdadeiro homem ou de uma verdadeira mulher, pois "eu ponho o acento em Mim, e não em ser Homem. O homem não é nada, senão enquanto atributo Meu (minha propriedade); sucede com a humanidade o mesmo que com a virilidade e a feminilidade" ${ }^{\prime 2}$.

Se a fixidez do sujeito era negada, a mediação institucionalizada que marcaria as relações intersubjetivas também seria alvo dessa desconstrução. A leitura que Emma Goldman propõe no resgaste do pensamento stirneriano é corrosiva, uma vez que coloca acento na ruptura dos deveres sociais. Ao versar sobre a perniciosidade do modelo cristão

\footnotetext{
${ }_{9}^{9}$ GOLDMAN, Anarquismo: lo que realmente significa, p. 30.

${ }^{10}$ STIRNER, O Único e sua propriedade, p. 62.

${ }^{11}$ Cf. SAORNIL, Horas de Revolución.

12 STIRNER, O Único e sua propriedade, p. 234-235.
} 
de individualidade abnegada, padrão particularmente deletério para as mulheres, a autora afirmaria:

Muito mais benéfico é o individualismo extremo de Stirner e Nietzsche em vez da atmosfera de confinamento doentio da fé cristã. Se eles repudiam o altruísmo como um mal é por causa do exemplo contido no cristianismo, que fixa um prêmio ao parasitismo e à inércia, que dá à luz a todas as formas de desordens sociais que serão curadas com a pregação de amor condolência. ${ }^{13}$

A questão do "parasitismo" também seria levantada por Emma Goldman em ocasião do supracitado ensaio Matrimônio e Amor (1911), reiterando-se o argumento da autora segundo o qual o sufocamento da autonomia das mulheres seria historicamente essencializado, chegando a ser assimilado pelas próprias em uma espécie de subsunção interna de si mesmas sob conceitos dogmáticos aprendidos desde tenra infância. Relegada ao papel de "parasita" 14 do marido, a figura hegemônica da mãe e esposa devotaria sua vida ao dever e autoabnegação. A recusa desses liames sociais, através da adoção de um posicionamento individualista, marcaria um gesto de revolta contra tal contrato econômico.

Destarte, na medida em que dialoga com a negação dos deveres sociais que se consubstanciariam em fantasmas corporificados na própria consciência dos indivíduos, Emma Goldman afirmaria: "é absolutamente necessário que as mulheres guardem esta lição: sua liberdade irá até onde for seu poder de libertar-se"15. Reiterando o prisma do indivíduo enquanto célula basilar do anarquismo, a militante encontra em Stirner a ideia da "singularidade" como um potencial de insurgência que esboroa os limites entre foro privado e público e alça o eu-ilimitado ao patamar de devir. Colocar em xeque as ficções sociais teleológicas - seja por meio da arte, seja por meio da filosofia - equivaleria a romper com um dos grilhões que aprisionam a subjetividade.

O cotejo entre a obra do filósofo supracitado com o ensaio da anarquista intitulado O Sufrágio feminino (1911) revela uma afinidade inicial com um prisma niilista que, causticamente, dissolve as esperanças de setores feministas em relação ao alcance da equidade por meio das fímbrias do sistema legal. Se desconstruir a delegação do governo-de-si a instâncias externas já constituiria um exercício de emancipação, chancelas institucionais somente reforçariam a exclusão da humanidade. É nesse diapasão que a ideia de uma "libertação do conceito de liberdade"16 operada por Stirner ganha forma no feminismo antipredicativo de Goldman. Atrelar-se a uma causa dogmática sufocaria qualquer potencialidade de revolta. Para o filósofo, as obrigações morais, políticas e racionais deveriam ser solapadas em prol de uma associação voluntária de "egoístas".

Embora subscrevesse a concepção de uma militância antilegalista, o solipsismo em que resvala Stirner seria insuficiente para o ideário libertário de Emma Goldman, que encontraria em um anelo ideal a sua plena expressão. Ou seja, se Stirner conduz seu manifesto radical de modo a rechaçar a delegação do "eu" a identidades externas, Emma Goldman levaria esse princípio para o âmbito da emancipação das mulheres. O "nada" de Stirner incita

\footnotetext{
13 GOLDMAN, O fracasso do Cristianismo, p.1.

${ }^{14}$ Cf. GOLDMAN, Matrimonio y Amor, p. 98.

${ }^{15}$ GOLDMAN, The Individual, Society and the State, p.95.

${ }^{16}$ STIRNER, O Único e sua propriedade, p. 202.
} 
a pensar nessa autodeterminação proposta pela anarquista, uma vez que o gesto inicial do filósofo é o da autodeterminação: "o nada que eu sou não o é no sentido da vacuidade, mas antes o nada criador, o nada a partir do qual eu próprio, como criador, tudo crio" ${ }^{17}$. Essa premissa negadora também seria adotada por Goldman, que se ancoraria na ideia de uma individualidade antipredicativa. Contudo, para a anarquista, ser "nada" corresponderia a encontrar na ideia de "humanidade" a linha de fuga das expectativas sociais. No que tange à exclusão feminina, ela diagnosticaria:

Tendo em conta que o grande infortúnio das mulheres tem sido o fato de ser olhada ou como anjo ou como demônio, a sua verdadeira salvação reside na possibilidade de ser colocada na terra, ou seja, em ser considerada humana e, portanto, sujeita a todas as loucuras e erros humanos. ${ }^{18}$

Se as mediações, tais como o "altruísmo" cristão, são rechaçadas por Goldman, tendo como inspiração o niilismo de Stirner e Nietzsche, o mesmo não se pode dizer acerca das representações humanas expressas por meio da arte e da filosofia radicais. Propugnando o alcance de uma consciência que se manifestaria a partir de uma "individualidade humana" em seu epítome, a anarquista entreveria nas linguagens artísticas engajadas a possibilidade de manifestação da potencialidade subjetiva.

Em um trecho elucidativo de sua defesa do eu-singular e da relevância da associação dessas subjetividades singulares para o alcance de uma causa anarquista, Emma Goldman asseveraria:

Vou começar com uma afirmação: deixando de lado todas as teorias políticas e econômicas, as distinções de classe e de raça, as fronteiras artificialmente traçadas entre os direitos das mulheres e os dos homens, afirmo que há um ponto no qual essas diferenças podem se encontrar e se fundir em um todo perfeito. A paz ou a harmonia entre os sexos e os indivíduos não dependem necessariamente de um nivelamento superficial dos seres humanos nem requerem a eliminação das particularidades e dos traços individuais. O problema que temos de considerar hoje e que seria preciso resolver é o seguinte: como ser você mesmo e ainda estar em unidade com os outros, como sentir-se em profunda comunhão com todos os outros seres humanos e conservar intactas suas próprias qualidades? ${ }^{19}$

A análise do excerto supracitado conduziu a autora do presente ensaio a três inferências: a de que a individualidade não é tida como algo que se possa categorizar de forma identitária, predicativa, a partir de uma alteridade excludente, a de que o gesto de não se abnegar compõe a estratégia de luta anarquista, e a de que o tecido social humano não é tido como uma abstração irrealizável.

\footnotetext{
${ }^{17}$ STIRNER, O Único e sua propriedade, p. 10.

18 GOLDMAN, El Sufragio Femenino, p. 119.

${ }^{19}$ GOLDMAN, The Tragedy of Woman's Emancipation, p. 91.
} 
Enquanto o conceito de humanidade, para Max Stirner, seria uma ideia fixa que submeteria os indivíduos a uma subserviência racional da modernidade - revisitando-se o culto religioso a partir da adoração de uma verdade absoluta -, para Emma Goldman este seria o vislumbre de um potencial de equidade anarquista. O filósofo é peremptório: "aquele que vive para uma grande ideia, uma boa causa, uma doutrina, um sistema, uma missão sublime, não pode se entregar a nenhum prazer mundano, a nenhum interesse egoísta" ${ }^{20}$. Em contraposição a essa perspectiva, o pensamento goldmaniano encontra no ideal anarquista um limiar de conciliação entre a satisfação dos desejos subjetivos e o engajamento do gênio individual a uma causa.

Seria impossível descurar da premissa anarquista subjacente ao feminismo antidogmático de Goldman. O elo indissolúvel entre a emancipação da mulher e o alcance de uma consciência libertária humana se faz presente em muitos escritos que advogam em prol de uma guinada psicológica como semente da insurgência social. Segundo suas palavras, "ainda que o fator econômico seja relevante, não é suficiente. A renovação da humanidade necessita da inspiração e da força vivificadora de um ideal" ${ }^{21}$. Ver-se-á, a seguir, pois, como o teatro ibseniano representaria a construção de individualidades humanas em devir, sintetizando o anelo anarquista goldmaniano.

\section{O drama social moderno e a emergência da individualidade}

A Henrik Ibsen (1828-1906) foi atribuído o designativo de criador do teatro realista moderno, uma vez que o dramaturgo rompeu com convenções do teatro burguês e colocou em cena temáticas polêmicas, que escancaravam dilemas morais. Em uma de suas assertivas, o autor norueguês exporia sua afinidade com o ethos anarquista: "O Estado é uma maldição para o indivíduo" 22 . Com efeito, a obra ibseniana atrairia a atenção de Goldman por descortinar a emergência de mulheres e homens que romperiam com o verniz social patriarcal, burocrático e moralista.

À desconstrução stirneriana de um ethos religioso que pautaria a conduta do sujeito, Emma Goldman conjugava seu apreço pelo teatro como forma de articular uma estrutura de afetos antiautoritária. Segundo suas enfáticas palavras,

Ainda mais abrangente é o drama moderno, como o fermento do pensamento radical e o disseminador de novos valores. Pode parecer um exagero atribuir ao drama moderno um papel tão importante. Mas um estudo do desenvolvimento de ideias modernas na maioria dos países provará que o drama conseguiu levar para casa grandes verdades sociais, verdades geralmente ignoradas quando apresentadas de outras formas. ${ }^{23}$

\footnotetext{
20 STIRNER, O Único e sua propriedade, p.99.

${ }^{21}$ GOLDMAN, The Individual, Society and the State, p. 14.

22 SILVA, Ibsen no Brasil, p. 210.

${ }^{23}$ GOLDMAN, The Modern Drama: a powerful disseminator of radical thought, p. 102.
} 
O teatro ibseniano, nesse sentido, seria propalado nas conferências goldmanianas como linguagem engajada que solapava "os falsos ídolos sociais" ${ }^{24}$. As personagens dilaceradas das peças de Ibsen seriam entrevistas pela anarquista como representações iconoclastas do sujeito racional, a serviço do Estado, e das instituições correlatas que instilariam deveres na mentalidade individual. Rejeitando a assunção de "falsos ídolos", heróis nacionalistas e convenções sociais, o teatrólogo asseverava: "combater a ideia de Estado, representar a iniciativa individual e sua ligação com a ordem psíquica como a condição essencial a qualquer associação, este é o começo de uma liberdade valorosa" 25 .

O solipsismo em que resvala o pensamento de Max Stirner não poderia definir o apreço de Emma Goldman pela arte engajada como uma mediação social possível. Desse modo, as tramas ibsenianas, ao colocarem em cena subjetividades que se confrontam com o tecido social e abandonam o seio familiar para desenvolver suas potencialidades humanas, seriam tidas como porta-voz de um possível contexto libertário, uma realidade associativa factível.

Para Tereza Menezes, estudiosa dos dramas de Ibsen,

Se Freud quebrou a unidade do sujeito como aquele ser da consciência, foi Ibsen que criou as condições para que ele "contracenasse" com personagens em processo de reelaboração de sua subjetividade. É este sujeito, filho da filosofia, da psicanálise e da arte, que Ibsen expõe ao público, convidando-o a entrar em contato com o outro de si mesmo. ${ }^{26}$

Efetivamente, enunciar-se-ia uma preocupação com a consciência de si como elemento social. As relações intersubjetivas no bojo da esfera privada, antes marcadas por uma espécie de inviolabilidade patriarcal, ganhariam visibilidade no âmbito das peças de desfecho imprevisível. Ou seja, longe de se esgotar em idiossincrasias do sujeito, as montagens do teatrólogo teciam liames nada idealistas com as instituições e costumes sociais. Justamente essa ruptura com as pièces bien faites que atrairia a admiração de Emma Goldman, pois a anarquista veria um posicionamento transgressor nas indefinições do caráter e nas intencionalidades multifacetadas dos protagonistas antimaniqueístas das peças ibsenianas.

Em uma passagem de sua autobiografia, a anarquista defenderia a conjugação dos ideais coletivistas do anarquista Kropotkin com a revolta do indivíduo ibseniano, afirmando:

Sustentávamos que o anarquismo não implicava em uma eleição entre Kropotkin e Ibsen, mas abarcava os dois. Enquanto Kropotkin havia analisado em profundidade as condições sociais que conduzem à revolução, Ibsen havia descrito a luta psicológica que culmina na revolução da alma humana. ${ }^{27}$

\footnotetext{
${ }^{24}$ GOLDMAN, The social Significance of the Modern Drama, p. 8.

${ }^{25}$ MENEZES, A Hermenêutica do Sujeito, p. 55-56.

${ }^{26}$ MENEZES, Ibsen e o novo sujeito da modernidade, p. 114.

${ }^{27}$ GOLDMAN, Vivendo Minha Vida, p.293.
} 
Um dos pontos fulcrais da militância goldmaniana, a saber, a desmontagem da aquiescência das mulheres em relação ao que ela designa como "puritanismo", dialogaria, pois, com o protagonismo de personagens que assumiriam as contracondutas e operariam uma espécie de "transvaloração dos valores" ao questionarem sua existência enredada em exclusões morais e políticas. O conceito de "contraconduta", cunhado por Michel Foucault, incita a pensar nessa autoconstituição da mulher propugnada por Goldman, a qual se descolaria dos parâmetros morais de feminilidade. Já a ideia de "transvaloração de valores", forjada por Nietzsche - autor que a anarquista admirava expressamente -, aponta para um niilismo ativo no qual a destruição transitória dos signos dominantes precede uma afirmação dos desejos subjetivos para além de injunções externas ao indivíduo.

A emergência de subjetividades que se autoquestionam, cindidas entre a realização de suas pulsões e os imperativos sociais, marcaria indelevelmente o teatro de Henrik Ibsen, representando o acento criativo que Emma Goldman conferia à militância anarquista e feminista.

\section{A Casa de Bonecas e o feminismo antipredicativo}

A filosofia radical, como se observou, entraria no repertório militante de Emma Goldman como um gesto de assunção do "eu" e, por conseguinte, de uma dessubjetivação da mulher em relação aos predicados hegemônicos reiteradamente atribuídos a ela. Esse exercício de desconstrução, porém, encontraria na linguagem do drama social moderno um meio de alavanca para a perspectiva de uma sociedade "outra". A subjetividade em devir que caracterizaria as personagens ibsenianas seria posta em destaque por Goldman, na medida em que sua expressão teatral sinalizaria o alcance de uma consciência insubmissa. Para a autora, "Ibsen havia descrito a luta psicológica que culmina na revolução da alma humana, a revolta da individualidade". E acrescenta: "nada poderia ser mais desastroso, para nossas ideias, que ignorar o efeito do interno sobre o externo, dos motivos e necessidades psicológicos sobre as instituições existentes" ${ }^{28}$.

É vislumbrando o teatro engajado como bastião de resistência que Emma Goldman atribuiria à peça Casa de Bonecas (1879) um manifesto de combate ao dever social que anula a individualidade da mulher, enredando-a a um casamento prostrante. $\mathrm{Na}$ trama da peça, a protagonista Nora abandona o lar após afirmar sua subjetividade em contraposição aos modelos de assunção da maternidade e matrimônio. A autora leria essa recusa à submissão como um laivo de uma sociedade em que a equidade entre os sexos teria lugar. Sublinhando o diálogo central desse movimento de resgate de si, Goldman afirmaria:

Existe algo mais degradante para a mulher do que viver com um estranho e ter filhos para ele? No entanto, a mentira da instituição do casamento decreta que ela continuará a fazê-lo, e a concepção social do dever insiste em que, por causa dessa mentira, ela não precisa ser outra coisa que um brinquedo, uma boneca, um não-ser. ${ }^{29}$

\footnotetext{
${ }^{28}$ GOLDMAN, Vivendo Minha Vida, p. 293.

${ }^{29}$ GOLDMAN, The social Significance of the Modern Drama, p.13.
} 
A anulação da humanidade de Nora seria um apontamento que Goldman destacaria tendo em vista o desmascaramento da antinomia vida privada/vida social que condenaria a mulher à primeira esfera. Ademais, o sufocamento dos potenciais desejantes por meio de um contrato inscreveria a sociedade em uma estrutura de alienação das individualidades. Aquilo que se convencionou designar como "micropolítica" já significava, para a anarquista, a única via plausível para uma guinada social.

O excerto emblemático a que Goldman faria alusão traz um diálogo corrosivo das convenções e pensamentos massificados que tolheriam a possibilidade de um autogoverno da mulher:

Helmer. É exasperante! Você pode abandonar seus deveres mais sagrados dessa maneira?

Nora . Como você chama meus "deveres mais sagrados"?

Helmer. Você me pergunta isso? Seus deveres para com seu marido e filhos.

Nora. Tenho outros deveres igualmente sagrados.

Helmer. Impossível! Que deveres você quer dizer?

Nora. Meus deveres para comigo mesma.

Helmer. Antes de tudo, você é esposa e mãe.

Nora. Não acredito mais nisso. Penso que, antes de tudo, sou um ser humano, tanto quanto você - ou, pelo menos, tentarei me tornar um. Sei que a maioria das pessoas concorda com você, Torvald, e o diz em livros. Mas, daqui em diante, não posso ficar satisfeita com o que a maioria das pessoas diz e com o que está nos livros. Devo pensar nas coisas por mim mesma e tentar esclarecer sobre elas ... eu morava aqui havia oito anos com um homem estranho e tinha três filhos - Oh! Não suporto pensar nisso - posso me despedaçar! ... Não posso passar a noite na casa de um homem estranho. ${ }^{30}$

É interessante notar como Emma Goldman, ao comentar sobre a trama, sublinha não a reivindicação de direitos legais pela mulher, mas justamente o reconhecimento por parte desta última da perda de sua individualidade. Ao destrinchar o enredo, a anarquista emprega alguns termos que oferecem indícios de como a peça endossa seu argumento do não-binarismo entre indivíduo e sociedade, intimidade e esfera pública. Um desses conceitos seria o de "consciência": para a militante, Nora passaria por um processo de despertar da consciência adormecida. Emma Goldman interpreta o devassar dessa vida recôndita no lar e a exposição desse movimento interno de conscientização como uma das incumbências do teatro. Ou seja, a progressão dos acontecimentos externos/paralelos importaria menos do que o desenvolvimento da alma autônoma da protagonista, a qual paulatinamente se manifestaria através da reconciliação entre indivíduo e humanidade.

O autorreconhecimento de Nora enquanto ser-humano seria lido por Goldman como a expressão da individualidade humana: ao assumir o "cuidado de si", a personagem poderia voltar a se relacionar com a sociedade a partir de interações que não implicassem em sua submissão. Para Michel Foucault, o "cuidado de si" seria coextensivo ao governo dos outros, de modo que essa relação inextricável abriria ensejo a um movimento de

${ }^{30}$ IBSEN, Peças Escolbidas 3, p. 298. 
dessubjetivação/subjetivação em devir que teria potencial para engendrar inflexões sociais. Conforme o autor defende, "Ocupar-se consigo não é pois, uma simples preparação momentânea para a vida; é uma forma de vida" ${ }^{1}$. Tem-se, aí, uma concepção de existência que Goldman propugnava e exercitava: suas redes de amizade, conferências e escrita de uma autobiografia redundariam em uma perspectiva de inextricável relação entre ética e estética.

Como Emma Goldman vislumbraria na assunção dos desejos individuais um gatilho para a construção de uma sociedade antipatriarcal? Para a anarquista, a construção de relações libertárias só seria facultada a partir da agência de minorias. Analogamente, Michel Foucault argumentaria que a massa viabilizaria o sistema de governamentalidade do pastorado moderno. Se para a anarquista somente os indivíduos poderiam cultivar uma força disruptiva capaz de gerar dissidência ante a uniformidade, ela encararia o teatro engajado como prémanifestação dessas ações diretas capazes de vencer a inércia da maioria.

Ao assujeitamento, condição exposta por Foucault, a narrativa transgressora do teatro contraporia uma subjetivação fora da ordem discursiva pré-estabelecida. Na obra Em defesa da Sociedade, Foucault sugere "não perguntar aos sujeitos como, por que, em nome de que direito eles podem aceitar deixar-se sujeitar, mas mostrar como são as relações de sujeição efetiva que fabricam sujeitos" ${ }^{32}$. O desvelamento cênico dessas relações assimétricas de poder seria abordado por Goldman como uma explicitação dos dispositivos de dominação instilados nos indivíduos por meio de "superstições" antes inquestionáveis.

A argumentação de Goldman parte, portanto, do gesto destrutivo de denúncia da subsunção social, isto é, da profanação do modelo socialmente sacralizado. Contudo, a anarquista não encerra a mensagem do drama social nessa etapa de auto-assunção-de-si. Conforme a anarquista aduz:

Quando Nora fecha atrás dela a porta da casa de sua boneca, ela abre amplamente o portão da vida para a mulher e proclama a mensagem revolucionária de que apenas a perfeita liberdade e comunhão criam um verdadeiro vínculo entre homem e mulher, encontrando-se a céu aberto, sem mentiras, sem vergonha, livre da escravidão do dever. ${ }^{33}$

Assim, Emma Goldman interpreta a peça ibseniana como uma busca do sujeito no foro sagrado da família para o confronto deste não só com seus próprios sentimentos, mas para assumi-los socialmente, suscitando uma transvaloração dos valores em um movimento do micro ao macro. Esse processo, análogo ao de autopoiese descrito por Eliane Accioly Fonseca, é de tear a própria subjetividade, assumir a proa de uma poética de potencialidades e singularidades subjetivas. Enraizando-se na própria vida, a arte ofereceria experimentações para o sujeito-processualidade. Segundo a última autora,

A criação da autorreferência seria uma sucessão de procedimentos: o ser humano só pode se voltar para si mesmo e, assim, experimentar a

\footnotetext{
${ }^{31}$ FOUCAULT, A Hermenêutica do Sujeito, p. 446.

${ }^{32}$ FOUCAULT, Em defesa da sociedade, p. 319.

33 GOLDMAN, The social Significance of the Modern Drama, p. 13.
} 
continuidade de ser e, em seguida, conhecer tanto a si mesmo quanto o mundo, após ter sido reconhecido anteriormente por outro humano. ${ }^{34}$

Nessa esteira de pensamento, é possível considerar que Emma Goldman não propugnava direitos iguais a mulheres e homens, mas uma ruptura com as próprias concepções de "direitos", "deveres", sugerindo relações de alteridade que deveriam passar, primeiramente e eminentemente, pelo crivo da consciência individual. Afinal de contas, como já apontou Maria Lacerda de Moura: "de que vale a igualdade de direitos jurídicos e políticos para meia dúzia de privilegiadas, tiradas da própria casta dominante, se a maioria feminina continua vegetando na miséria da escravidão milenar?”35.

\section{Considerações finais}

Se o único compromisso de Emma Goldman era com a dissidência, com a militância sem fórmulas e regras de conduta superiores, isso não teria como corolário a adesão a um individualismo solipsista. Sua perspectiva respondia a um feminismo sem adjetivos que inscreve mulheres e homens no bojo de um potencial humano de reconstrução. Destarte, a reconciliação entre indivíduo e sociedade seria possível desde que os liames intersubjetivos respondessem aos desejos individuais, sem a delegação dos potenciais humanos a "direitos" chancelados externamente e de forma transcendente. A subjetividade radical deveria ser comprometida com a destruição e a criatividade, sob risco de alicerçar novas modalidades de autoridade que se alimentam da cumplicidade inscrita em identidades servis.

A fratura da subjetividade, provocada tanto pela ontologia radical quanto pelo teatro de identidades nômades, se inscreve em uma micropolítica que, para Emma Goldman, significava romper com a reedição de novos ídolos e tiranias. Assim, o feminismo como um programa fixo, isto é, como um dogma que inscreve as mulheres em papéis prédeterminados, também seria visto como óbice à autonomia. Para a anarquista, se a mulher quisesse ser mãe ou amante, ela poderia sê-lo, não obstante a liberdade fosse encarada por muitas de suas contemporâneas majoritariamente como a garantia de espaço no mercado de trabalho ou direito ao voto.

Nesse sentido, a defesa de individualidades humanas assume um sentido filosófico de antirrenúncia de si para propiciar o florescimento de associações voluntárias. As subjetividades autônomas, por conseguinte, só poderiam ser individualidades autoconscientes na medida em que não descurassem de seus próprios desejos em prol de conceitos absolutos de "liberdade". Ao germinar no próprio sujeito e depois reverberar na constituição das relações intersubjetivas, a autonomia teria o revoltar-se como ponto de partida. O devir subjacente à recusa de uma teleologia moral corresponde ao apreço da anarquista por um teatro de personagens sem destino, que fazem da emancipação um processo de dessubjetivação e subjetivação perene. O livre-pensar estimulado pela filosofia stirneriana e pelo teatro ibseniano ameaçaria, assim, as instituições hegemônicas, os saberes e valores orientados pela Igreja e pela lógica autoritária por meio de sua ação-direta corporificada nas conferências de Emma Goldman.

${ }^{34}$ FONSECA, Corpo-de-sonho: arte e psicanálise, p. 31.

${ }^{35}$ MOURA, A mulher é uma degenerada., p. 12. 


\section{Referências Bibliográficas}

FONSECA, Eliane Accioly. Corpo-de-sonbo: arte e psicanálise. São Paulo: Annablume, 1999.

FOUCAULT, Michel. A Hermenêutica do Sujeito. São Paulo: Martins Fontes, 2006.

Em defesa da sociedade: curso no Collège de France (1975-1970). 2. ed. São Paulo: Martins Fontes, 2010.

GOLDMAN, Emma. "Anarquismo: lo que realmente significa” (1911a). In: La Palabra como Arma. Buenos Aires: Libros de Anarres; La Plata: Terramar, 2010.

"Matrimonio y Amor" (1911b). In: La Palabra como Arma. Buenos Aires: Libros de Anarres; La Plata: Terramar, 2010.

"O fracasso do Cristianismo" (1913). Disponível em: $<\underline{\text { https://theanarchistlibrary.org/library/emma-goldman-the-failure-of-christianity }>}$ Acesso em 17 de fevereiro de 2020.

"El Sufragio Femenino" (1911c). In: La Palabra como Arma. Buenos Aires: Libros de Anarres; La Plata: Terramar, 2010.

"The Individual, Society and the State" (1940) Disponível em: $<$ https://theanarchistlibrary.org/library/emma-goldman-the-individual-society-and-thestate $>$ Acesso em 17 de fevereiro de 2020.

"The Modern Drama: a powerful disseminator of radical thought" (1910). In: Anarchism and other Essays. Disponível em: < https://theanarchistlibrary.org/library/emmagoldman-anarchism-and-other-essays $>$ Acesso em 17 de fevereiro de 2020.

"The social Significance of the Modern Drama" (1914).

Disponível em: < $\quad$ https://theanarchistlibrary.org/library/emma-goldman-the-socialsignificance-of-the-modern-drama.pdf $>$ Acesso em 23 de julho de 2019.

. “The Tragedy of Woman's Emancipation” (1906). Disponível em: $<$ https://theanarchistlibrary.org/library/emma-goldman-the-tragedy-of-woman-semancipation?v $=1614901700>$ Acesso em 17 de fevereiro de 2020.

Vivendo Minha Vida. Curitiba: L-Dopa Publicações, 2015.

GUATTARI, Félix; ROLNIK, Suely. Micropolitica: cartografias do desejo. Rio de Janeiro: Vozes, 1986.

IBSEN, Henrik. Peças Escolhidas 3. Livros Cotovia: Lisboa, 2008.

MENEZES, Tereza. Ibsen e o novo sujeito da modernidade. São Paulo: Perspectiva, 2006. 
MOURA, Maria Lacerda de. A mulher é uma degenerada. $3^{a}$ edição. Rio de Janeiro: Civilização Brasileira, 1982.

SAORNIL, Lucía Sanchez. Horas de Revolución. Barcelona: Editado por el Sindicato Único del Ramo de Alimentación de Barcelona, 1937.

SILVA, Jane Pessoa da. Ibsen no Brasil. Dissertação de Mestrado em Letras. São Paulo, Universidade de São Paulo, 2007.

STIRNER, Max. O Único e sua propriedade. São Paulo: Martins Fontes, 2009. 